06,13

\title{
Влияние высокотемпературного отжига на ориентацию вектора униполярности в тонких пленках цирконата-титаната свинца
}

\author{
(c) А.Г. Канарейкин ${ }^{1}$, Е.Ю. Каптелов ${ }^{1}$, С.В. Сенкевич ${ }^{1}$, И.П. Пронин ${ }^{\llbracket, 1}$, \\ А.Ю. Сергиенко ${ }^{2}$ О.Н. Сергеева ${ }^{3,4}$ \\ ${ }^{1}$ Физико-технический институт им. А.Ф. Иофрфе РАН, \\ Санкт-Петербург, Россия \\ ${ }^{2}$ Институт управления образованием Российской академии образования, \\ Санкт-Петербург, Россия \\ ${ }^{3}$ Тверской государственный университет, \\ Тверь, Россия \\ ${ }^{4}$ Московский технологический университет (МИРЭА), \\ Москва, Россия \\ ฯ E-mail: Petrovich@mail.ioffe.ru
}

(Поступила в Редакцию 11 мая 2016 г.)

Рассматриваются причины изменения ориентации вектора естественной униполярности в результате нагревания до температуры Кюри тонкопленочного конденсатора Pt/PZT/Pt (PZT — цирконат-титанат свинца), сформированного на подложке $\mathrm{TiO}_{2} / \mathrm{SiO}_{2} / \mathrm{Si}$. Тонкие слои $\mathrm{PZT}$, содержащие незначительный избыток оксида свинца, сформированы ex situ методом высокочастотного магнетронного распыления при вариации температуры отжига (кристаллизации фазы перовскита) в диапазоне $580-650^{\circ} \mathrm{C}$. Предполагается, что реориентация вектора униполярности в слое PZT вызвана сменой механизма кристаллизации фазы перовскита с ростом температуры отжига.

Работа выполнена при частичной финансовой поддержке Министерства образования и науки РФ (грант 14.Z50.31.0034) и гранта РФФИ № 16-02-00632.

\section{1. Введение}

Явление естественной униполярности (в англоязычной литературе используется термин „self-polarization“ - „самопроизвольная поляризация“) [1-25] в тонких сегнетоэлектрических пленках наблюдается достаточно часто в отличие от объемных кристаллов [26,27]. В ряде случаев (естественная) униполярность тонких слоев может достигать значений, близких к величинам остаточной или спонтанной поляризации $[1,4,6,8]$, и в этом качестве пленки представляют интерес для практического применений в микроэлектромеханике, ИК-технике и других приложениях $[1,28,29]$. Причины возникновения такого состояния подробно исследуются в последние два десятилетия, в основном в сегнетоэлектриках со структурой перовскита: твердых растворах цирконата-титаната свинца $\left(\mathrm{Pb}\left(\mathrm{Zr}_{1-x} \mathrm{Ti}_{x}\right) \mathrm{O}_{3}\right.$ или $\left.\mathrm{PZT}\right)$ и титанате бария. Анализ накопленного экспериментального материала показывает, что это явление вызывается совместным действием сил электрической и механической природы [1-4,6,17,20,22].

Для понимания природы эффекта важным, но при этом малоизученным остается вопрос о причинах, приводящих к различной ориентации вектора униполярности. В экспериментах наблюдалось униполярное состояние, вектор которого был направлен как в сторону подложки [6-9,12-15,19,24,25], так и в противоположном направлении - к свободной поверхности тонкой пленки $[1,5,7,11,12,20,22]$. Предположения о причинах той или иной ориентации вектора по существу сводятся к двум основным физическим механизмам.

Согласно первому механизму, при формировании пленок PZT в отсутствие верхнего электрода тонкопленочного сегнетоэлектрического конденсатора ориентация вектора униполярности определяется знаком объемного заряда, сформированного вблизи нижнего интерфей$\mathrm{ca}$, электрическое поле которого частично или полностью поляризует тонкий сегнетоэлектрический слой (сегнетослой). Поле отрицательного объемного заряда будет ориентировать сегнетоэлектрические диполи по направлению к нижнему интерфейсу - к подложке (рис. $1, a)$. Соответственно положительный объемный заряд приведет к образованию самополяризации, ориентированной к свободной поверхности пленки $[11,12,17,22]$. После нанесения на сегнетослой верхнего электрода разрушение поля объемного заряда (и как следствие самополяризованного состояния) достигается нагреванием конденсаторной структуры выше температуры Кюри $T_{c}[5,9,12,15]$. Согласно [12,17], происходит перераспределение (симметричное или несимметричное) подвижных зарядов между нижним и верхним интерфейсами путем их захвата на глубокие приповерхностные ловушки и образование приповерхностных объемных зарядов (рис. $1, b$ и $c$ ). Встречные электрические поля, создаваемые этими зарядами, приводят к симметризации гистерезисных зависимостей, а также формированию перетянутых (или зауженных) петель гистерезиса, до- 


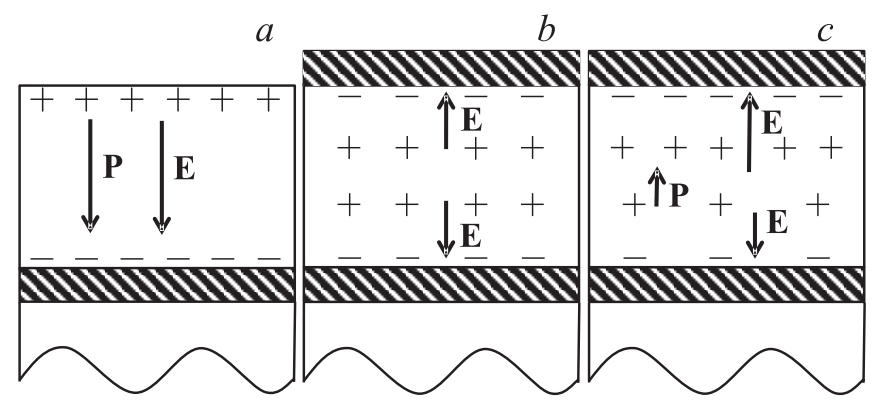

Рис. 1. Схематическое изображение образования естественноуниполярного состояния $(a)$, его изменения после нанесения верхнего электрода и нагревания выше $T_{c}(b, c)$.

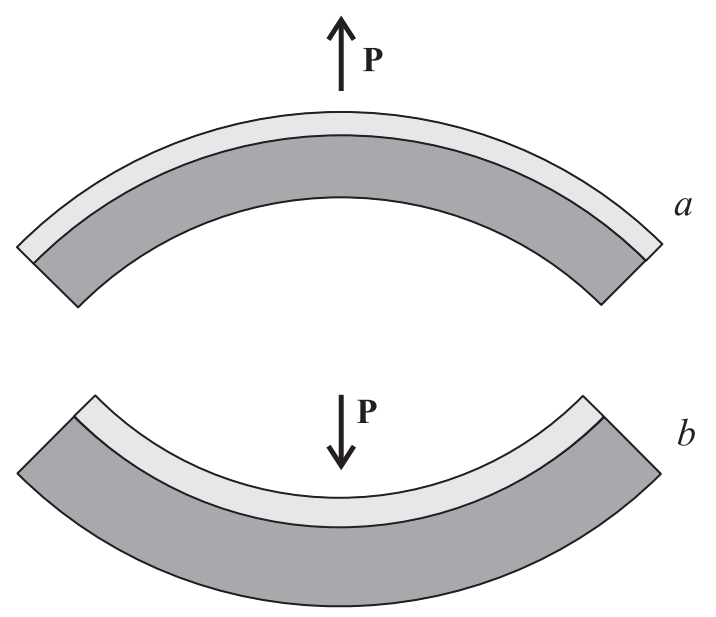

Рис. 2. Направление вектора флексоэлектрической поляризации в тонких пленках в зависимости от характера изгиба подложки.

полнительных максимумов на вольт-фарадных $(C-V)$ зависимостях $[5,9,12,15]$.

Вторым механизмом, который может влиять на ориентацию вектора униполярности, является воздействие на сегнетослой двумерных механических напряжений со стороны подложки, возникающих из-за разности температурных коэффициентов линейного расширения сегнетослоя и подложки или в случае эпитаксиального роста пленок различия в параметрах их кристаллических решеток $[1-4,8,17,22]$. Результатом этого воздействия являются градиент механических напряжений, ориентированный в направлении нормали к плоскости подложки, и изгиб системы пленка-подложка выпуклостью либо вверх (рис. 2, a), либо вниз (рис. 2, $b$ ). Следствием такого изгиба является образование диполей и вызванного ими внутреннего электрического поля (флексоэлектрический эффект). Было показано, что в тонких сегнетоэлектрических слоях флексоэлектрический эффект является причиной образования макроскопической (сегнетоэлектрической) поляризации, а изменение направления изгиба приводит к реориентации спонтанной поляриза- ции [30,31]. Однако экспериментальное подтверждение образования естественной униполярности в тонких сегнетоэлектрических пленках за счет действия подобного механизма до сих пор отсутствует.

Целью настоящей работы является сравнительная оценка воздействия сил электрической и механической природы и их изменения в результате нагревания выше $T_{c}$, приводящих к реориентации вектора униполярности в тонких слоях PZT.

\section{2. Объекты и методы исследования}

Объектами исследования являлись тонкие пленки PZT, сформированные двухстадийным (ex situ) методом выскочастотного магнетронного распыления керамической мишени, состав которых соответствовал области морфотропной фазовой границы $(x=0.46)[12,15]$. Пленки PZT толщиной $1000 \mathrm{~nm}$ осаждались при низкой температуре подложки, а затем для кристаллизации фазы перовскита подвергались высокотемпературному отжигу на воздухе при температурах $T_{\mathrm{ann}}=580-650^{\circ} \mathrm{C}$. Подложками служили оксидированные кремниевые пластины со слоем $\mathrm{SiO}_{2}$ толщиной $700 \mathrm{~nm}$, адгезионным слоем $\mathrm{TiO}_{2}$ толщиной $20 \mathrm{~nm}$ и слоем платины толщиной $80 \mathrm{~nm}\left(\mathrm{Pt} / \mathrm{TiO}_{2} / \mathrm{SiO}_{2} / \mathrm{Si}\right)$, выполняющим роль нижнего электрода. Материалом верхних электродов также служила платина.

Микроструктура и состав тонких пленок исследовались при помощи растрового электронного микроскопа EVO-40 (Carl Zeiss), оборудованного энергодисперсионной приставкой INCA, а также атомно-силового микроскопа „Смена“ (НТ-МДТ, Зеленоград), параметры кристаллической решетки определялись с помощью дифрактометра ДРОН-7. Наличие униполярного состояния в сегнетослоях определялось по асимметрии петель диэлектрического гистерезиса $(P-V)$, полученных с использованием модифицированной схемы Сойера-Тауэра, и вольт-фарадных $(C-V$ или $\varepsilon-V)$ характеристик (измеритель иммитанса Е7-20). Измерение пироэлектрического отклика (величина которого пропорциональна степени униполярности сегнетослоя) проводилось в динамическом режиме [15] в диапазоне частот $10-10^{3} \mathrm{~Hz}$.

\section{3. Экспериментальные результаты и их обсуждение}

Структурные исследования показали, что сегнетослои представляли собой однофазную поликристаллическую структуру, характеризующуюся преимущественной ростовой $\langle 110\rangle$-текстурой. Средний размер перовскитовых зерен составлял $\sim 200 \mathrm{~nm}$. Содержание свинца в пленках превышало стехиометрическое соотношение $\mathrm{Pb} /(\mathrm{Zr}+\mathrm{Ti})$, обычно равное единице. Избыток свинца (в виде его оксида) уменьшался от значения $\mathrm{Pb} /(\mathrm{Zr}+\mathrm{Ti})$ $\sim 1.105(10.5 \%)$ при $T_{\text {ann }}=580^{\circ} \mathrm{C}$ до $\sim 1.03(3 \%)$ при $T_{\text {ann }}=650^{\circ} \mathrm{C}$ (рис. 3 ). 


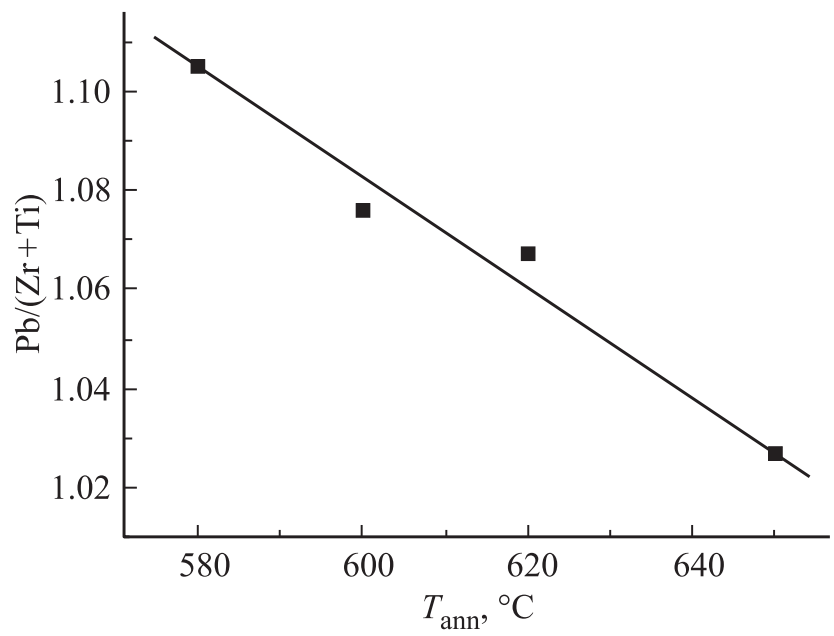

Pис. 3. Изменение содержания избыточного свинца в пленках PZT в зависимости от $T_{\text {ann }}$.

Характерные $C-V$ (или $\varepsilon-V$ ) и $P-V$ зависимости для ,девственных“ пленок PZT и нагретых до или выше температуры Кюри, пленок PZT, полученные при комнатной температуре, показаны на рис. 4 и 5. Сдвиг и асимметрия гистерезисных кривых в сторону отрицательных напряжений обычно связываются с избыточным оксидом свинца, генерирующим кислородные вакансии и отрицательный объемный заряд на нижнем интерфейсе сегнетослоя [12,17,22]. Небольшая величина внутреннего поля $E_{\text {int }}$ для образцов „девственных“ пленок, отожженных при $T_{\text {ann }}=580^{\circ} \mathrm{C}$, составляла $\sim 5 \mathrm{kV} / \mathrm{cm}$ (рис. 4,a) и связана как с относительно большой толщиной сегнетослоя $(1000 \mathrm{~nm})$, так и с невысоким содержанием избыточного свинца. С ростом $T_{\text {ann }}$ значение $E_{\text {int }}$ уменьшалось практически до нуля, а $C-V$-кривые становились близкими к симметричным (рис. 4, $c$ ).

Нагревание образцов выше температуры Кюри приводило к существенному изменению характера гистерезисных зависимостей: направление вектора внутреннего поля изменялось и величина поля несколько возрастала с ростом $T_{\text {ann }}$ (рис. $\left.4, c, d\right)$. В наиболее явном виде асимметрия (и ее изменение) проявлялась на форме петель диэлектрического гистерезиса. В частности, ориентация вектора внутреннего поля не изменялась в пленках, сформированных при $580^{\circ} \mathrm{C}$ (рис. $\left.5, a, b\right)$, тогда как в пленках, сформированных при $620^{\circ} \mathrm{C}$, вектор поля был ориентирован по направлению к свободной поверхности сегнетослоя (рис. $5, c, d)$.

Аналогично изменялось и направление пироэлектрического тока образцов, которое определялось по отношению к фазе опорного сигнала, воспроизводящего форму модуляции теплового потока. Положительное значение
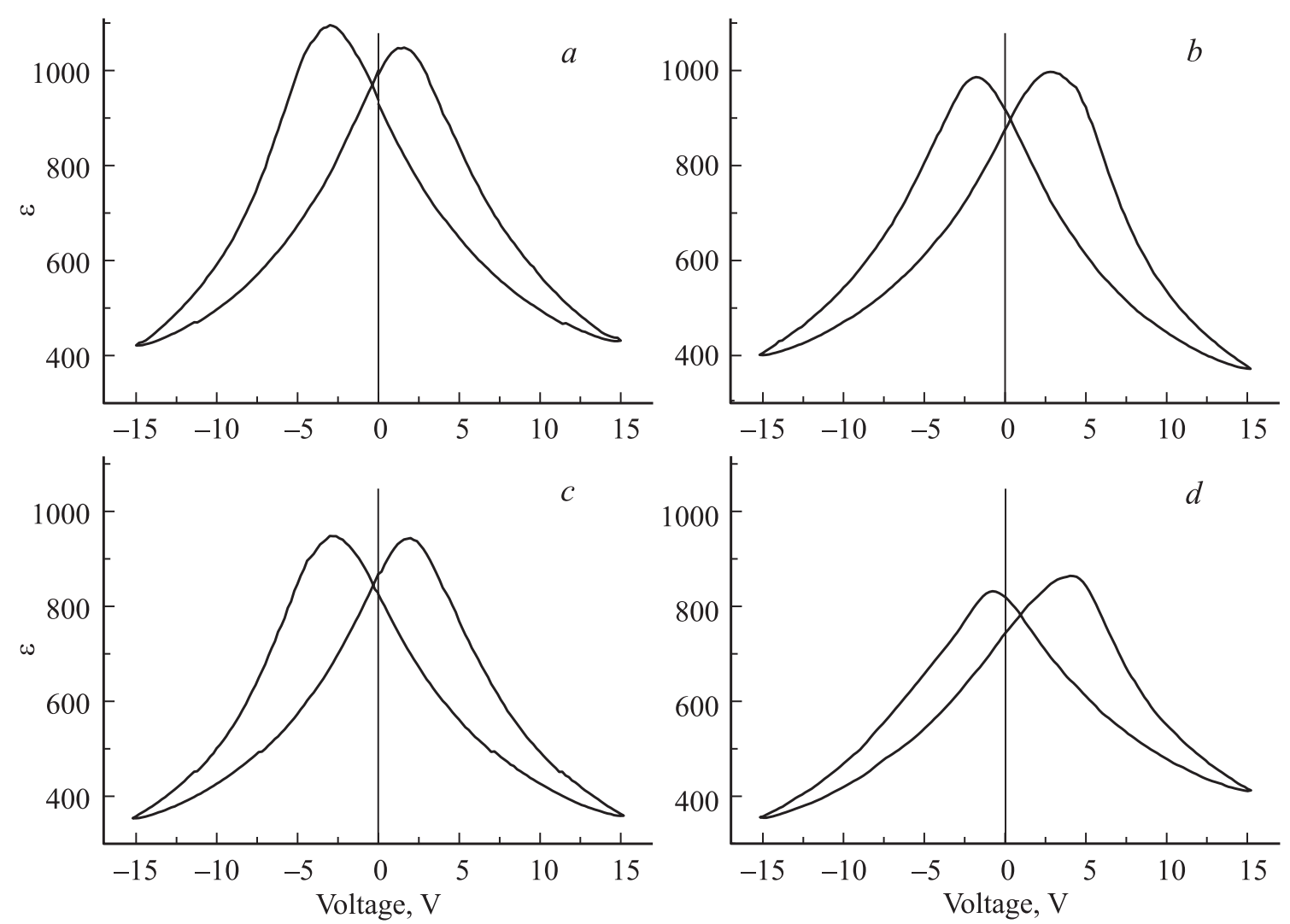

Рис. 4. $C-V(\varepsilon-V)$-зависимости, характерные для пленок PZT, кристаллизация фазы перовскита которых осуществлялась при $T_{\text {ann }}=580(a)$ и $620^{\circ} \mathrm{C}(c)$, а также непосредственно после нагревания конденсаторных структур РZT выше $T_{c}\left(T_{\text {ann }}=580(b)\right.$ и $\left.620^{\circ} \mathrm{C}(d)\right)$. 

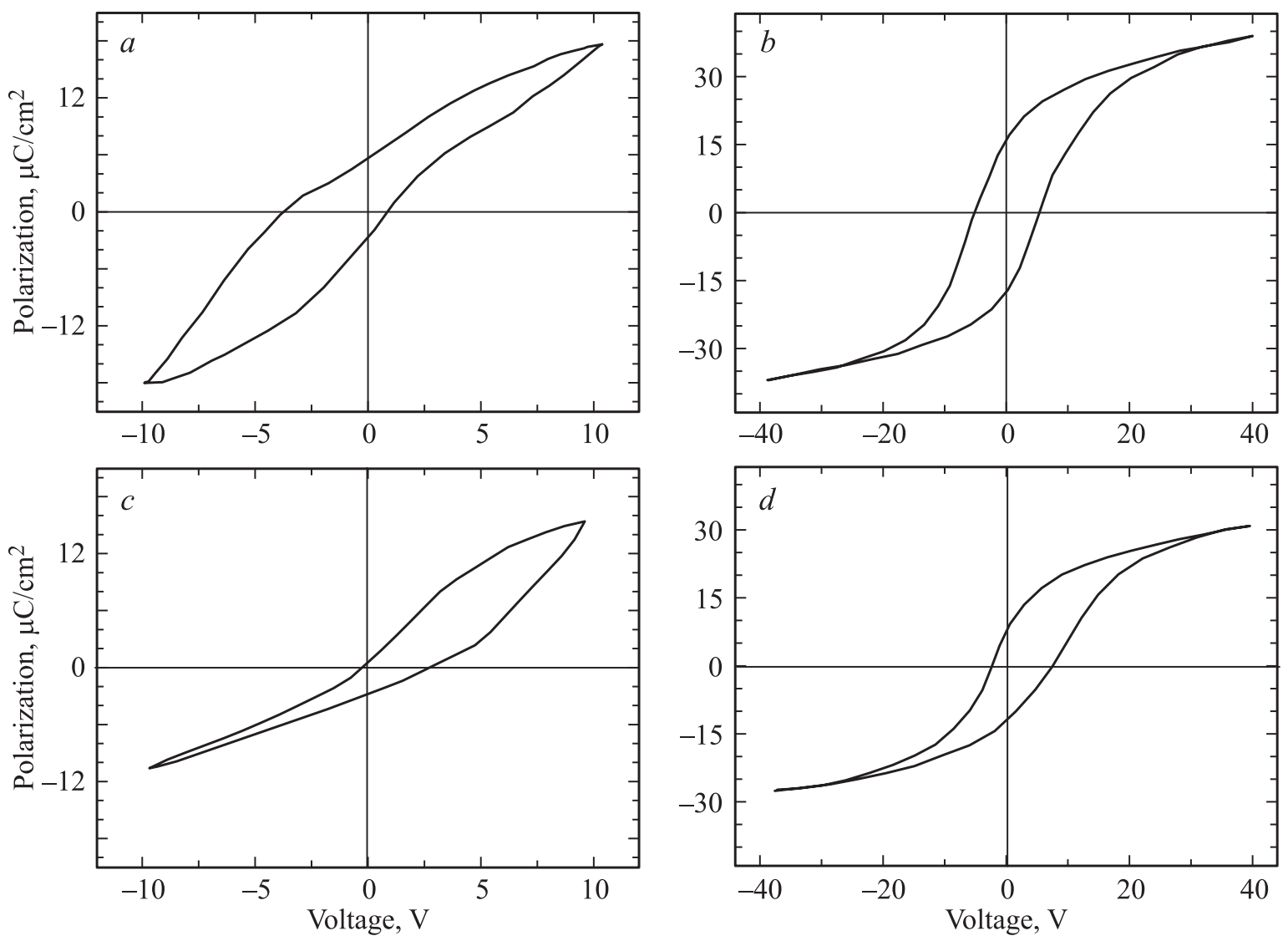

Рис. 5. Петли диэлектрического гистерезиса, измеренные при двух значениях амплитуды переменного напряжения, характерные для конденсаторных структур PZT, нагретых выше $T_{c}\left(T_{\mathrm{ann}}=580(a, b)\right.$ и $\left.620^{\circ} \mathrm{C}(c, d)\right)$. Частота измерения $1 \mathrm{kHz}$.

амплитуды измеренного пиротока в образцах, сформированных при $T_{\mathrm{ann}}=580^{\circ} \mathrm{C}$, соответствующее ориентации вектора униполярности в направлении к нижнему электроду, с ростом $T_{\text {ann }}$ заменялось отрицательным значением, свидетельствующим о реориентации вектора униполярности, а сама величина отрицательного пироотклика несколько возрастала (рис. 6).

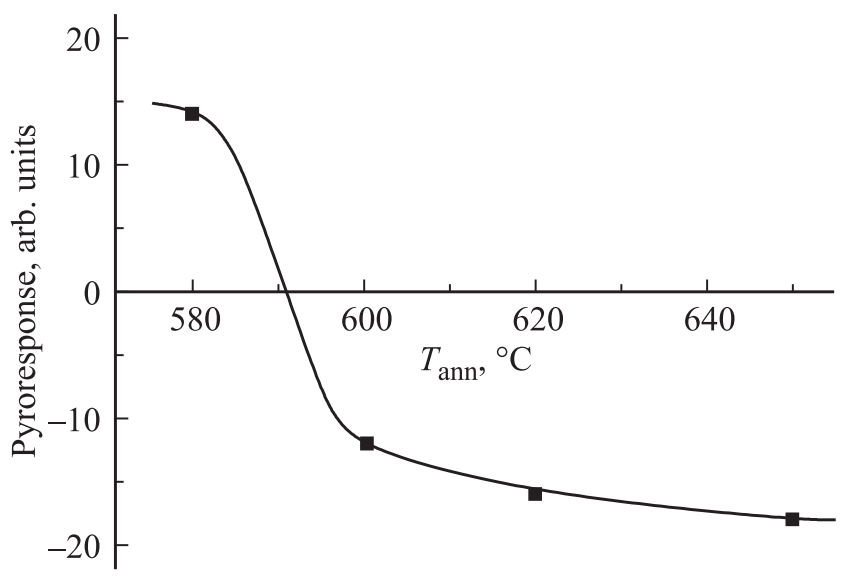

Pис. 6. Изменение знака сигнала пироотклика в тонкопленочном конденсаторе Pt/PZT/Pt после нагревания структуры выше $T_{c}$ в зависимости от $T_{\text {ann. }}$.
Таким образом, приведенные выше данные подтверждают полученный ранее результат о реориентации вектора униполярности в пленках, нагретых до температур выше $T_{c}[15]$.

Для объяснения этого эффекта будем исходить из предположений, сделанных на основе ранее полученных экспериментальных результатов.

1. Униполярное состояние формируется объемным зарядом на нижнем интерфейсе сегнетослоя в отсутствие верхнего электрода. Присутствие избыточного свинца в сегнетослое (в виде его оксида) способствует образованию подвижных (примесных) носителей заряда электронного типа, которые, закрепляясь на глубоких ловушках нижнего интерфейса, формируют отрицательный объемный заряд. Действие электрического поля этого заряда ориентирует сегнетоэлектрические диполи (части либо всего объема тонкой пленки в зависимости от величины поля и толщины сегнетослоя) в направлении к подложке (рис. 1,a).

2. Нагревание выше $T_{c}$ при наличии симметричных верхнего и нижнего электродов приводит к перераспределению объемного заряда на обоих интерфейсах сегнетослоя. Это ведет к появлению локальных электрических полей, ориентированных навстречу друг другу (рис. $1, b, c)$. 
3. Согласно [21], зародышеобразование фазы перовскита может происходить как вблизи свободной поверхности сегнетослоя, так и вблизи нижнего интерфейca. С ростом температуры отжига $T_{\text {ann }}$ (при которой происходит кристаллизация фазы перовскита) механизм зарождения фазы перовскита на свободной поверхности сегнетослоя, сопровождающийся выдавливанием избыточного оксида свинца в нижнюю часть сегнетослоя, заменяется механизмом зарождения фазы на нижнем интерфейсе, в результате чего избыточный оксид свинца выдавливается в верхнюю часть сегнетослоя.

Таким образом, несмотря на симметрию электродов, асимметрия расположения избыточного свинца по толщине сегнетослоя (и связанная с ним асимметрия объемного заряда) изменяется с ростом $T_{\text {ann }}$, что может приводить к переориентации вектора униполярности.

Следует отметить, что вследствие выдавливания избыточного оксида свинца к свободной поверхности вероятность реориентации вектора внутреннего поля (и вектора униполярности) может возрастать из-за локального недостатка свинца в нижней части сегнетослоя, где атомное соотношение $\mathrm{Pb} /(\mathrm{Zr}+\mathrm{Ti})$ становится меньше единицы. В этом случае следует ожидать появления вакансий по свинцу, дырочного типа носителей заряда и формирования положительного объемного заряда вблизи нижнего интерфейса сегнетослоя. Для подтверждения этой версии необходимо исследовать образцы в широком интервале изменения концентрации свинца в PZT-пленке, для чего требуется проведение дополнительных исследований.

Существенный изгиб системы сегнетослой-кремниевая подложка, необходимый для проявления флексоэлектрического эффекта, может быть достигнут при наличии „достаточно толстого“ буферного слоя диоксида кремния $\left(\mathrm{SiO}_{2}\right)$, который формируется при высоких температурах в результате оксидирования подложки [32]. Если этот буферный слой $\mathrm{SiO}_{2}$ формируется только со стороны рабочей поверхности кремниевой подложки, то из-за более низкого температурного коэффициента линейного расширения $\mathrm{SiO}_{2}\left(\alpha_{\mathrm{SiO}_{2}} \approx 0.55 \cdot 10^{-6}{ }^{\circ} \mathrm{C}^{-1}\right)$, чем в кремнии $\left(\alpha_{\mathrm{Si}} \approx(2.5-4.4) \cdot 10^{-6}{ }^{\circ} \mathrm{C}^{-1}\right.$ в зависимости от температуры) [33], будет наблюдаться изгиб системы $\mathrm{SiO}_{2} / \mathrm{Si}$ выпуклостью вверх (рис. 2,a). Кроме того, формирование фазы перовскита в процессе высокотемпературного отжига (или in situ роста) будет происходить на искривленной поверхности подложки. Bсе это может способствовать формированию униполярного состояния, вектор которого будет ориентирован в направлении свободной поверхности сегнетослоя.

Наши оценки механических напряжений и величин изгиба в конкретной структуре $\mathrm{PZT} / \mathrm{SiO}_{2} / \mathrm{Si}$ (слои Pt и $\mathrm{TiO}_{2}$ не принимаем в расчет из-за их малой толщины) с использованием соотношений и подходов, взятых из работ [8] и [34], показали, что при комнатной температуре радиус изгиба составляет не менее $30-40 \mathrm{~m}$. Эта величина практически на два порядка больше радиусов изгибов, которые были достигнуты в экспериментах для переориентации спонтанной поляризации в тонких сегнетослоях титаната бария или PZT [30,31]. Таким образом, с высокой долей вероятности можно исключить из рассмотрения флексоэлектрический эффект как возможную причину образования униполярного состояния в тонком слое PZT.

\section{4. Заключение}

Мы экспериментально подтвердили, что высокотемпературный нагрев униполярных тонкопленочных конденсаторных структур Pt/PZT/Pt, сформированных на подложке $\mathrm{TiO}_{2} / \mathrm{SiO}_{2} / \mathrm{Si}$, приводит к изменению направления внутреннего поля и реориентации вектора униполярности. Предполагается, что причиной этого эффекта является изменение механизма кристаллизации фазы перовскита с ростом температуры отжига, при которой бо́льшая часть избыточного оксида свинца выдавливается к свободной поверхности сегнетослоя, где в результате нагревания и последующего охлаждения формируется отрицательный объемный заряд, превосходящий аналогичный заряд у нижнего интерфейса PZT-конденсатора.

\section{Список литературы}

[1] K. Ijima, R. Takayama, Y. Tomita, I. Ueda. J. Appl. Phys. 60, 2914 (1986).

[2] E. Sviridov, I. Sem, V. Alyoshin, S. Biryukov, V. Dudkevich. Mater. Res. Soc. Symp. Proc. 361, 141 (1995).

[3] G.A.C.M. Spierings, G.J.M. Dormans, W.G.J. Moors, M.J.E. Ulenaers, P.K. Larsen. J. Appl. Phys. 78, 1926 (1995).

[4] K. Abe, S. Komatsu, N. Yanase, K. Sano, T. Kamakubo. Jpn. J. Appl. Phys. 36 (Pt 1), 9B, 5846 (1997).

[5] E.G. Lee, J.S. Park, J.K. Lee, J.G. Lee. Thin Solid Films 310, 327 (1997)

[6] A.L. Kholkin, K.G. Brooks, D.V. Taylor, S. Hiboux, N. Setter. Integr. Ferroelectrics 22, 525 (1998).

[7] M. Kobune, H. Ishito, A. Mineshige, S. Fujii, R. Takayama, A. Tomozawa. Jpn. J. Appl. Phys. 37 (Pt 1), 9B, 5154 (1998).

[8] R. Bruchhaus, D. Pitzer, M. Schreiter, W. Wersing. J. Electroceram. 3, 151 (1999).

[9] S. Okamura, S. Miyata, Y. Mizutani, T. Nishida, T. Shiosaki. Jpn. J. Appl. Phys. 38 (Pt 1), 9B, 5364 (1999).

[10] H. Fujusawa, S. Nakashima, K. Kaibara, M. Shimizu, H. Niu. Jpn. J. Appl. Phys. 38 (Pt 1), 9B, 5392 (1999).

[11] S. Hiboux, P. Muralt. Integr. Ferroelectrics 36, 83 (2001).

[12] И.П. Пронин, Е.Ю. Каптелов, Е.А. Тараканов, В.П. Афанасьев. ФТТ 44, 1659 (2002).

[13] G. Suchaneck, T. Sandner, A. Deineka, G. Gerlach, L. Jastrabik. Ferroelectrics 289, 309 (2004).

[14] V.V. Shvartsman, A.V. Pankrashkin, V.P. Afanasjev, E.Yu. Kaptelov, I.P. Pronin, A.L. Kholkin. Integr. Ferroelectrics 69, 103 (2005).

[15] А.А. Богомолов, О.Н. Сергеева, Д.А. Киселев, Е.Ю. Каптелов, И.П. Пронин. Письма в ЖТФ 31, 11, 42 (2005).

[16] Z.J. Wang, H. Kokawa, H. Takizawa, M. Ichiki, R. Maeda. Appl. Phys. Lett. 86, 212903 (2005).

[17] В.П. Афанасьев, И.П. Пронин, А.Л. Холкин. ФТТ 48, 1143 (2006). 
[18] B.E. Watts. Proc. Appl. Ceram. 3, 1-2, 97 (2009).

[19] E.C. Lima, E.B. Araújo, I.K. Bdikin, A.L. Kholkin. Mater. Res. Bull. 47, 3548 (2012).

[20] X.-Y. Li, L. Chang, W.-X. Gao, G.-L. Yuan, J. Yin, Z.-G. Liu. AIP Adv. 3, 122101 (2013).

[21] В.П. Пронин, С.В. Сенкевич, Е.Ю. Каптелов, И.П. Пронин. ФTT 55, 92 (2013).

[22] J.-P. Chen, Y. Luo, Y. Ou, G.-L. Yuan, Y.-P. Wang, Y. Yang, J. Yin, G.-G. Liu. J. Appl. Phys. 113, 204105 (2013).

[23] E.C. Lima, E.B. Araújo, I.K. Bdikin, A.L. Kholkin. Ferroelectrics 465, 106 (2014).

[24] Б.М. Даринский, А.С. Сидоркин, Л.П. Нестеренко, А.А. Сидоркин. ФТТ 57, 536 (2015).

[25] В.В. Осипов, Д.А. Киселев, Е.Ю. Каптелов, С.В. Сенкевич, И.П. Пронин. ФТТ 57, 1748 (2015).

[26] F.T. Rogers, jr. J. Appl. Phys. 27, 1066 (1956).

[27] В.Г. Гавриляченко, В.П. Дудкевич, Е.Г. Фесенко. Кристаллография 13, 342 (1968).

[28] W. Eerenstein, N.D. Mathur, J.F. Scott. Nature 442, 759 (2006).

[29] N. Izyumskaya, Y.-I. Alivov, S.-J. Cho, H. Morkoç, H. Lee, Y.-S. Kang. Critical Rev. Solid State Mater. Sci. 32, 111 (2007).

[30] Э.В. Бурсиан, О.И. Зайковский, К.В. Макаров. Изв. АН СССР. Сер. физ. 33, 1098 (1969).

[31] A. Gruverman, B.J. Rodriguez, A.I. Kingon, R.J. Nemanich, A.K. Tagantsev, J.S. Cross, M. Tsukada. Appl. Phys. Lett. 83, 728 (2003).

[32] Основы технологии кремниевых интегральных схем. T. I. Окисление, диффузия, эпитаксия / Под ред. Р. Бургера, Р. Донована. Мир, М. (1969). 451 с.

[33] H. Watanabe, N. Yamada, M. Okaji. Int. J. Thermophys. 25, 1, 221 (2004).

[34] И.П. Пронин, Е.Ю. Каптелов, Н.Г. Хосина, В.П. Афанасьев. Письма в ЖТФ 30, 6, 70 (2004). 